\title{
Application of GTN ointment to facilitate spout eversion during ileostomy formation
}

\author{
A. J. Macdonald • K. Stevenson • A. Macdonald
}

Received: 9 September 2009/Accepted: 7 October 2010/Published online: 3 December 2010

(c) Springer-Verlag 2010

Normal or exaggerated smooth muscle contraction within the distal ileum may make spout eversion difficult when forming a loop or end ileostomy, resulting in oedema,

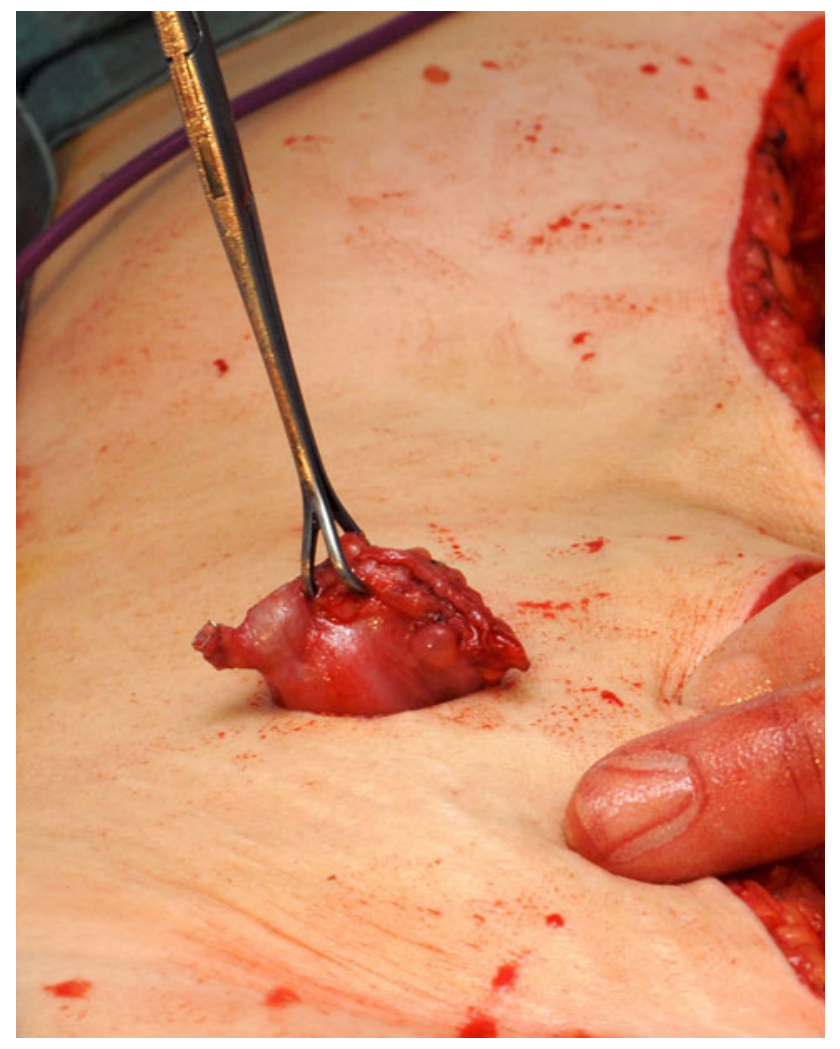

Fig. 1 The distal ileum is brought through the skin in the normal way

A. J. Macdonald · K. Stevenson · A. Macdonald ( $₫)$

Monklands Hospital, Airdrie, UK

e-mail: amacdcolorectal@aol.com
A. J. Macdonald
e-mail: alisdairmacdonald@nhs.net

bleeding and inadequate eversion. Glyceryl Trinitrate (GTN), a nitric oxide donor, relaxes ileal smooth muscle. Application of a standard paraffin-based GTN (2\%) ointment to the serosal surface of the externalised small bowel induces temporary ileal relaxation. Ileostomy formation is rendered easier and less traumatic, and this technique is now used routinely in our department (Figs. 1, 2, 3, 4).

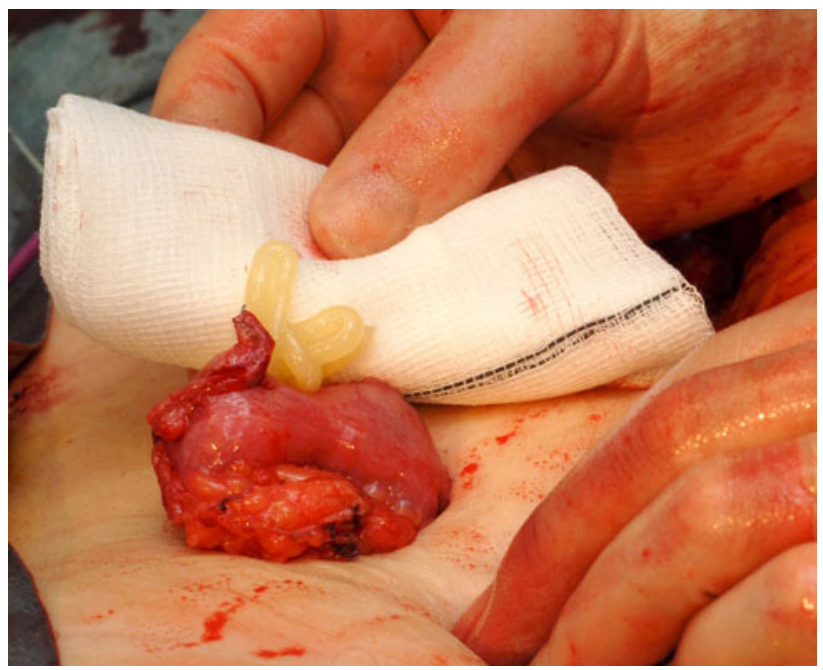

Fig. 2 Paraffin-based 2\% GTN ointment is applied to the serosal surface of the externalised bowel and the abdomen is closed 


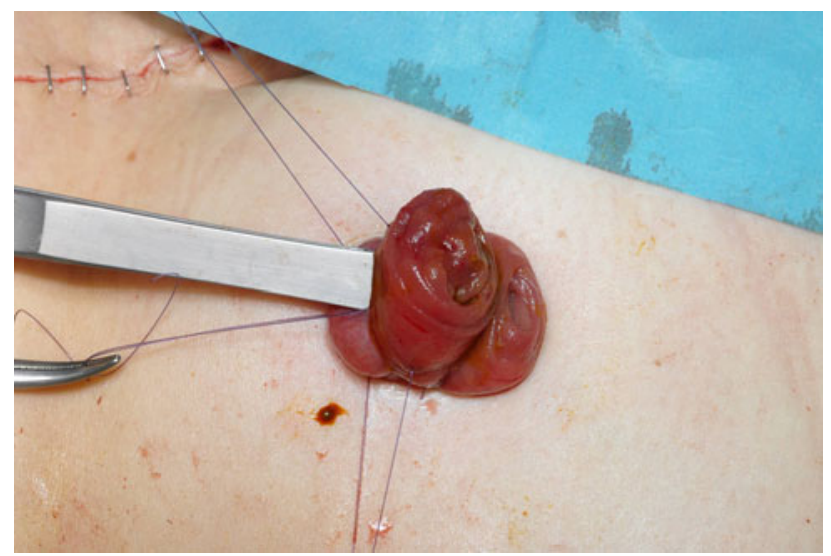

Fig. 3 The smooth muscle of the terminal ileum remains relaxed during manipulation allowing easy eversion and formation of the ileal spout

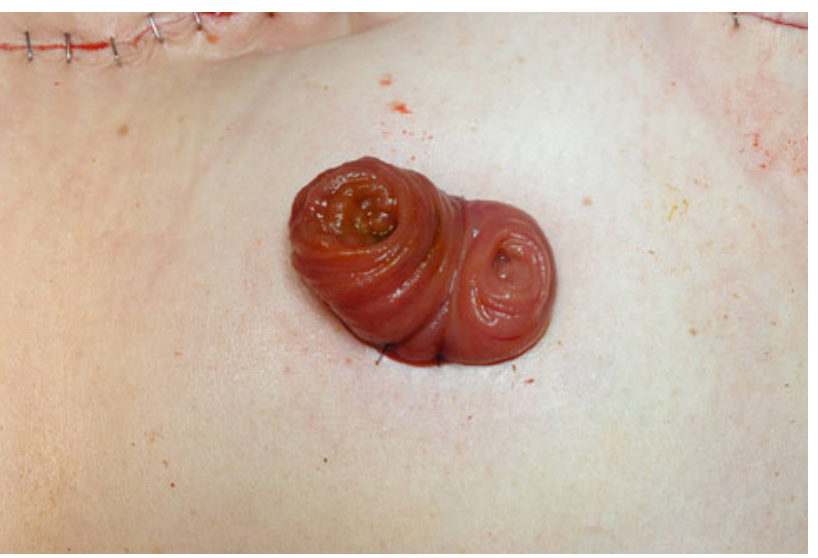

Fig. 4 Completed ileostomy 